\title{
The association between sarcopenia and the physical function of patients with stroke: A systematic review and meta-analysis
}

\author{
Irene J Su, Yi Li, Li Chen
}

Shantou University Medical College, 22 Xinling Road, Shantou 515041, Guangdong Province, China

Article Info

\section{Article Notes}

Received: April 09, 2021

Accepted: April 27, 2021

\section{${ }^{*}$ Correspondence:}

Irene J Su, DNP, RNPMH-BC, Shantou University Medical

College, 22 Xinling Road, Shantou 515041, Guangdong

Province, China.

Email: suirene@hotmail.com; Tel: 248-873-8894

${ }^{\circledR} 2021$ Irene J Su. This article is distributed under the terms of the Creative Commons Attribution 4.0 International License.

\section{Keywords:}

sarcopenia

physical function; stroke

systematic review

meta-analysis
Abstract

Objectives: The purpose of this study is to identify whether there is an association between sarcopenia and physical function outcomes of patients with stroke.

Methods: A systematic search of Pubmed, Web of Science, Cochrane Library, Embase, China National Knowledge Infrastructure (CNKI), and Wanfang database was conducted to identify studies in Chinese and English from inception of the database to March 2021. Documents were checked for relevancy. Articles exploring the association between sarcopenia and physical function of patients with stroke were included. Quality of the literature was evaluated using the Newcastle-Ottawa scale tool. Stata 15.0 software was used to conduct meta-analysis.

Results: Eight studies met the criteria for inclusion. A meta-analysis of four studies showed that sarcopenia was related to an increased risk of poor physical function of patients with stroke (total OR=3.11, 95\% Cl: 2.22-4.34, $\mathrm{P}<0.0001)$. Descriptive analysis was performed in the rest of studies. Overall, a correlation between the two factors was found in patients with stroke. Some studies suggested a difference based on gender and severity of the disease condition. The studies included in this review were of high methodological quality. The Egger's test $(P=0.217)$ showed no publication bias.

Conclusions: This review concludes that sarcopenia is an independent predictive factor of physical function of patients with stroke. Clinicians should pay attention to gender differences and severity of disease condition. Therefore, screening, diagnosis, treatment, and prevention of sarcopenia should be part of the routine clinical practice when providing care to stroke patients.

\section{Introduction}

Sarcopenia is an under-evaluated and under-treated condition in patients with stroke. A systematic review reported that only 7 trials specifically assessed the prevalence of sarcopenia in stroke patients, with a pooled prevalence estimate of $42 \%{ }^{1}$. In addition, Recent clinical studies have shown that sarcopenia was observed in $53.6 \%$ of stroke patients ${ }^{2}$. Sarcopenia is defined as "progressive and systemic skeletal muscle disease related to increased occurrence of adverse health outcome" ${ }^{3}$. Causes of sarcopenia in patients with stroke, such as denervation, muscle mass loss, systemic catabolic activation, and muscle fiber displacement, can overlap. The occurrence of the problems can be complex and multi-factorial ${ }^{4}$. Currently, sarcopenia is frequently observed among the elderly population, leading to complications such as falls, disability, loss of independence, hospitalization, cognitive and mobility impairments, and mortality ${ }^{3,5-7}$. Therefore, early identification, diagnosis and treatment of sarcopenia are of great significance. 
Stroke is now the second leading cause of death and the primary cause of disability around the globe, and the burden of disease has increased dramatically ${ }^{8,9}$. In the early stages of stroke disease, predictors of long-term functional outcomes can identify which patients would benefit from specific rehabilitation services, facilitate early rehabilitation goals and discharge planning decisions, and promote care and rehabilitation services. Recently, some studies have indicated that sarcopenia among elderly patients is widely believed to be associated with functional outcomes ${ }^{10,11}$ and it is also correlated with a worse recovery of physical function and swallowing difficulties among hospitalized adults in rehabilitation ${ }^{2,12}$. Of note, in addition to the degree of neurological deficit assessed by the National Institutes of Health Stroke Scale ${ }^{13}$, assessment of sarcopenia may be a quantitative predictor of the functional prognosis in patients with stroke. To our knowledge, there has been no previous systematic review on the relationship between sarcopenia and physical function of patients with stroke. In this study, physical function was defined as ability regarding basic physical and cognitive activities such as walking or reaching, as well as the routine activities of daily living, including eating, bathing, dressing, transferring, and toileting. The purpose of this systematic review is to identify whether there is an association between sarcopenia and physical function outcomes of this patient population.

\section{Methods}

\section{Search strategy}

The following database were searched for relevant studies published in the English and Chinese languages: Pubmed, Web of science, Cochrane Library, Embase, China National Knowledge Infrastructure (CNKI), and Wanfang from inception of the database to March 2021. The search strategy included $\mathrm{MeSH}$ terms and their associated free words. Keywords are as follows: "Sarcopenia", "Muscular atrophy", "Muscle loss", and "Muscle weakness"; "Recovery of function", "Activities of daily living", "Functional status", "Physical fitness", and "Physical functional performance"; "Stroke", "Cerebrovascular accident", "Apoplexy", "Cerebral hemorrhage", and "Brain Vascular Accident", etc. References of the studies were checked to find other relevant studies.

\section{Eligibility criteria and selection of studies}

Inclusion criteria:

1. Confirmed stroke diagnosis on computed tomography or magnetic resonance imaging scan

2. Studies that explored the association between sarcopenia and physical function among patients with stroke

3. Prospective or retrospective observational studies meeting the above criteria.

\section{Exclusion criteria:}

1. Unpublished or duplicate studies, conference abstracts.

2. Randomized controlled trials (RCTs).

3. Studies with low methodological quality.

Two investigators independently conducted literature screening based on the data extraction and inclusion criteria. In case of disagreement or discrepancy, there would be a discussion to negotiate a solution until an agreement was reached.

\section{Quality assessment}

Two investigators independently assessed the methodological quality of each study, using the NewcastleOttawa Scale ${ }^{14}$. The scale assigned 2 points for assessment of group selection, 4 points for comparability, and 3 points for exposure/outcome. Quality scores ranged from 0 to 9 , with 7 to 9 indicating high quality, 4 to 6 indicating moderate quality, and 0 to 3 indicating low quality.

\section{Statistical analysis}

The odds ratio (OR) was the risk estimation measure with a corresponding 95\% confidence interval (CI). Statistical heterogeneity was assessed by employing the $Q$ statistic and the $\mathrm{I}^{2}$ statistic. The $Q$ statistic was considered statistically significant at $\mathrm{p}<0.1$. When $\mathrm{I}^{2}$ values was $25 \%$, $50 \%$ and $75 \%$, it indicated the threshold of low, medium, or high heterogeneity, respectively ${ }^{15}$. The tests were considered statistically significant at $\mathrm{p}<0.05$. Publication bias was determined using Egger's regression test at $\mathrm{p}<$ $0.05^{16}$. All analyses were conducted using Stata (version 15.0). In addition, some studies used descriptive analyses due to differences in the definitions, measurements, and outcomes of both dependent and independent variables.

\section{Results}

\section{Study selection}

5165 articles were identified. Duplicate articles were excluded $(n=1502)$. After the initial screening, another 3663 articles were excluded because they did not meet the inclusion criteria based on the abstract or title. After fulltext review of the remaining 19 studies, a total of 8 studies were selected in strict adherence to the inclusion and exclusion criteria. Review of the references of the included studies added no additional articles. All included studies used a cohort study design and involved a total of 1310 patients. The PRISMA flow chart is shown in Figure $1^{17}$.

\section{Methodological quality}

Details of the quality assessment of all included articles are shown in Table 1 . The mean quality assessment score 
Figure 1 PRISMA 2009 Flow Diagram
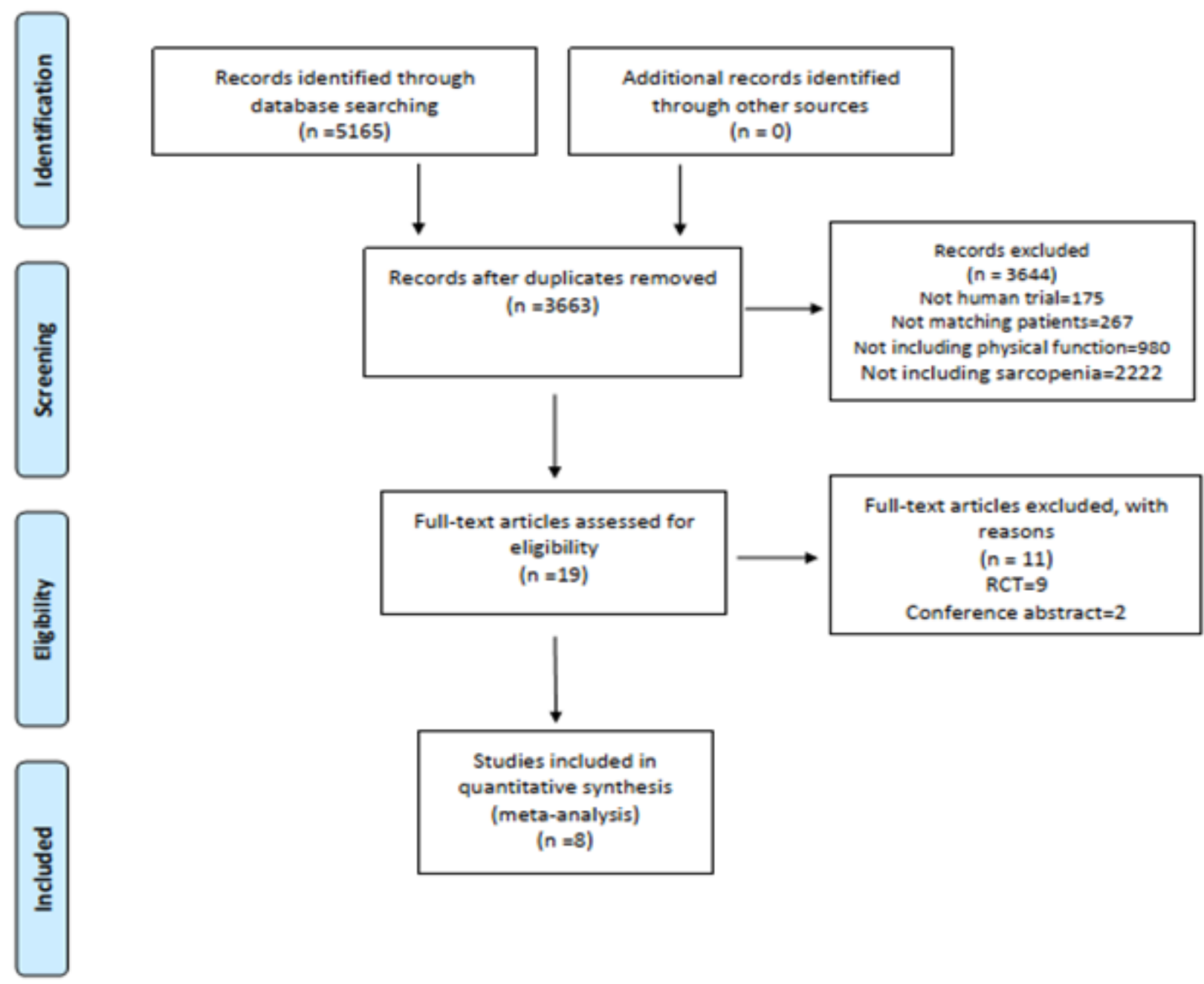

Mooined from: Moner D, Uberas A, Tetzlart J, Atman DG. The PRISMA Group (2009). Preferred Reporting Rems for Systemats Revlews and Meta-Analyses: The PRISMA Statement. PLOS Med 6(6): e1000097. dol:10.1371/joumal.pmed 1000097

For more information, visit www.prismo-statement.org.

Figure 1.

was 7.5, indicating overall high quality of all studies. No studies were excluded due to low quality.

\section{Characteristics of the studies}

The 8 studies $^{18-25}$ were published between $2017^{22}$ and $2020^{19-21,23,24}$, and their characteristics are shown in Table 2. They all demonstrated an association between sarcopenia and poorer physical function outcome. The included studies used different measures to assess sarcopenia and physical function outcomes of patients with stroke. Among these studies, the outcome measures used were the modified Rankin scale $(\mathrm{mRS})^{18-21}$, Modified Barthel Index $(\mathrm{MBI})^{22}$, and the Functional Independence Measure motor domain score (FIM-M) ${ }^{23-25}$. Four of these studies used the FIM or MBI to assess the activities of daily living (ADLs) status. Moreover, the diagnosis measure of sarcopenia differed in 
Table 1. Quality assessment of the included studies

\begin{tabular}{|l|c|c|c|c|c|}
\hline \multicolumn{1}{|c|}{ Study } & $\begin{array}{c}\text { Selection of participants } \\
\text { (0-4) }\end{array}$ & $\begin{array}{c}\text { Comparability of } \\
\text { participants (0-2) }\end{array}$ & $\begin{array}{c}\text { Assessment of } \\
\text { outcomes (0-3) }\end{array}$ & $\begin{array}{c}\text { Evaluate and control } \\
\text { confounding factors }\end{array}$ & $\begin{array}{c}\text { Total score } \\
\text { (0-9) }\end{array}$ \\
\hline Masafumi Nozoe,2019 & 3 & 2 & 3 & Yes & Yes \\
\hline Takafumi Abe,2020 & 4 & 2 & 2 & Yes & 8 \\
\hline Youbin Yi,2017 & 3 & 2 & 2 & Yes & 7 \\
\hline Yongjun Jang,2019 & 4 & 2 & 3 & Yes \\
\hline Ken Ohyama,2019 & 3 & 2 & 2 & Yes & 7 \\
\hline Tatsuya Matsushita,2019 & 3 & 2 & 2 & Yes & 7 \\
\hline Hiroshi Irisawa,2020 & 3 & 2 & 2 & Yes & 7 \\
\hline Fumihiko Nagano,2020 & 3 & 2 & 2 & 7 \\
\hline
\end{tabular}

Table 2. Characteristics of the included studies

\begin{tabular}{|c|c|c|c|c|c|c|c|}
\hline Study, Year & Country & Setting & $\begin{array}{c}\text { No. of } \\
\text { participants }\end{array}$ & $\begin{array}{l}\text { No. of } \\
\text { female }\end{array}$ & $\begin{array}{l}\text { Mean age } \pm S D \\
\text { in years at } \\
\text { baseline }\end{array}$ & $\begin{array}{l}\text { Sarcopenia } \\
\text { diagnostic } \\
\text { criteria }\end{array}$ & $\begin{array}{l}\text { Physical } \\
\text { function } \\
\text { outcome }\end{array}$ \\
\hline $\begin{array}{l}\text { Masafumi Nozoe, } \\
2019\end{array}$ & Japan & acute phase hospital & 152 & 71 & $76 \pm 11$ & $\begin{array}{c}\text { SARC-F } \\
\text { Scale score } \geq 4\end{array}$ & $\mathrm{mRS}$ \\
\hline $\begin{array}{l}\text { TakafumiAbe, } \\
2020\end{array}$ & Japan & acute phase hospital & 107 & 36 & $76 \pm 10.4$ & $\begin{array}{c}\text { SMI } \\
\text { SMI: male }<7.0 \mathrm{~kg} / \mathrm{m} 2 \text {, female } \\
<5.7 \mathrm{~kg} / \mathrm{m} 2\end{array}$ & $\mathrm{mRS}$ \\
\hline $\begin{array}{l}\text { Youbin Yi, } \\
2017\end{array}$ & South Korea & $\begin{array}{l}\text { the rehabilitation } \\
\text { unit }\end{array}$ & 127 & 63 & $68.6 \pm 14.9$ & $\begin{array}{c}\text { Grip strength } \\
\text { male }<26 \mathrm{~kg}, \\
\text { female }<18 \mathrm{~kg}\end{array}$ & $\mathrm{MBI}$ \\
\hline $\begin{array}{l}\text { Yongjun Jang, } \\
2019\end{array}$ & Korea & $\begin{array}{l}\text { department of } \\
\text { rehabilitation }\end{array}$ & 194 & 79 & $64.3 \pm 13$ & $\begin{array}{c}\text { Grip strength } \\
\text { male }<26 \mathrm{~kg} \text {, female }<18 \mathrm{~kg}\end{array}$ & $\mathrm{mRS}$ \\
\hline $\begin{array}{l}\text { Ken Ohyama, } \\
2019\end{array}$ & Japan & acute care hospital & 164 & 56 & $57.4 \pm 15.2$ & $\begin{array}{c}\text { Grip strength and SMI } \\
\text { grip strength: male }<26 \mathrm{~kg} \text {, female } \\
<18 \mathrm{~kg} \text { and } \mathrm{SMI} \text { male }<7.0 \mathrm{~kg} / \mathrm{m}^{2} \\
\text { female }<5.7 \mathrm{~kg} / \mathrm{m}^{2}\end{array}$ & $\mathrm{mRS}$ \\
\hline $\begin{array}{l}\text { Tatsuya Matsushit, } \\
2019\end{array}$ & Japan & $\begin{array}{c}\text { convalescent } \\
\text { rehabilitation wards }\end{array}$ & 267 & 117 & $72.5 \pm 13.2$ & $\begin{array}{c}\text { Grip strength and SMI } \\
\text { grip strength: male }<26 \mathrm{~kg} \text {, female } \\
<18 \mathrm{~kg} \text { and } \mathrm{SMI} \text { male }<7.0 \mathrm{~kg} / \mathrm{m}^{2} \\
\text { female }<5.7 \mathrm{~kg} / \mathrm{m}^{2}\end{array}$ & FIM \\
\hline $\begin{array}{l}\text { Hiroshi Irisawa, } \\
2020\end{array}$ & Japan & $\begin{array}{c}\text { stroke rehabilitation } \\
\text { unit }\end{array}$ & 179 & 90 & $79.7 \pm 11.5$ & $\begin{array}{c}\text { Body muscle percentage } \\
\text { (skeletal muscle mass/ } \\
\text { body weight } \% \text { ): male } \leq 30 \% \text {, } \\
\text { female } \leq 25 \%\end{array}$ & FIM \\
\hline $\begin{array}{l}\text { Fumihiko Nagano, } \\
2020\end{array}$ & Japan & $\begin{array}{l}\text { rehabilitation } \\
\text { hospital }\end{array}$ & 120 & 70 & $79.3 \pm 9.9$ & $\begin{array}{c}\text { Grip strength and SMI } \\
\text { grip strength: male }<28 \mathrm{~kg} \text {, female } \\
<18 \mathrm{~kg} \text { and } \mathrm{SMI} \text { male }<7.0 \mathrm{~kg} / \mathrm{m}^{2} \\
\text { female }<5.7 \mathrm{~kg} / \mathrm{m}^{2}\end{array}$ & FIM \\
\hline
\end{tabular}

these studies. Some studies used skeletal muscle quantity measured by bioelectrical impedance analysis (BIA) ${ }^{20,23}$ or the SARC-F scale ${ }^{18}$, whereas others employed either grip strength $^{21,22}$ or grip strength + skeletal muscle index (SMI) by BIA $^{19,24,25}$.

\section{Association of sarcopenia with physical function}

\section{Modified Rankin Scale (mRS)}

The relationship between sarcopenia and mRS was assessed in four studies ${ }^{18-21}$. No obvious heterogeneity was present in these studies. Therefore, we chose a fixedeffects model to report physical function comparing the sarcopenia and non-sarcopenia groups $\left(\mathrm{I}^{2}=29.5 \%\right)$. A meta- analysis of these studies showed that sarcopenia was related to an increased risk of poor physical function (total $\mathrm{OR}=3.11,95 \% \mathrm{CI}: 2.22-4.34, \mathrm{P}<0.0001$ ) as displayed in Figure 2. In addition, A study by Takafumi Abe ${ }^{[20]}$ indicated severity of the disease might be a confounding factor.

\section{Modified Barthel Index (MBI)}

The association between sarcopenia and MBI was evaluated in 1 study $^{22}$. dMBI was the change in MBI score between admission and discharge. Grip strength on the unaffected side (uGS) was positively associated with improvement in $\mathrm{MBI}$ at discharge $(\mathrm{P}=0.019)$. In addition, using multiple linear regression analysis, uGS was a significant independent predictor of the amount 


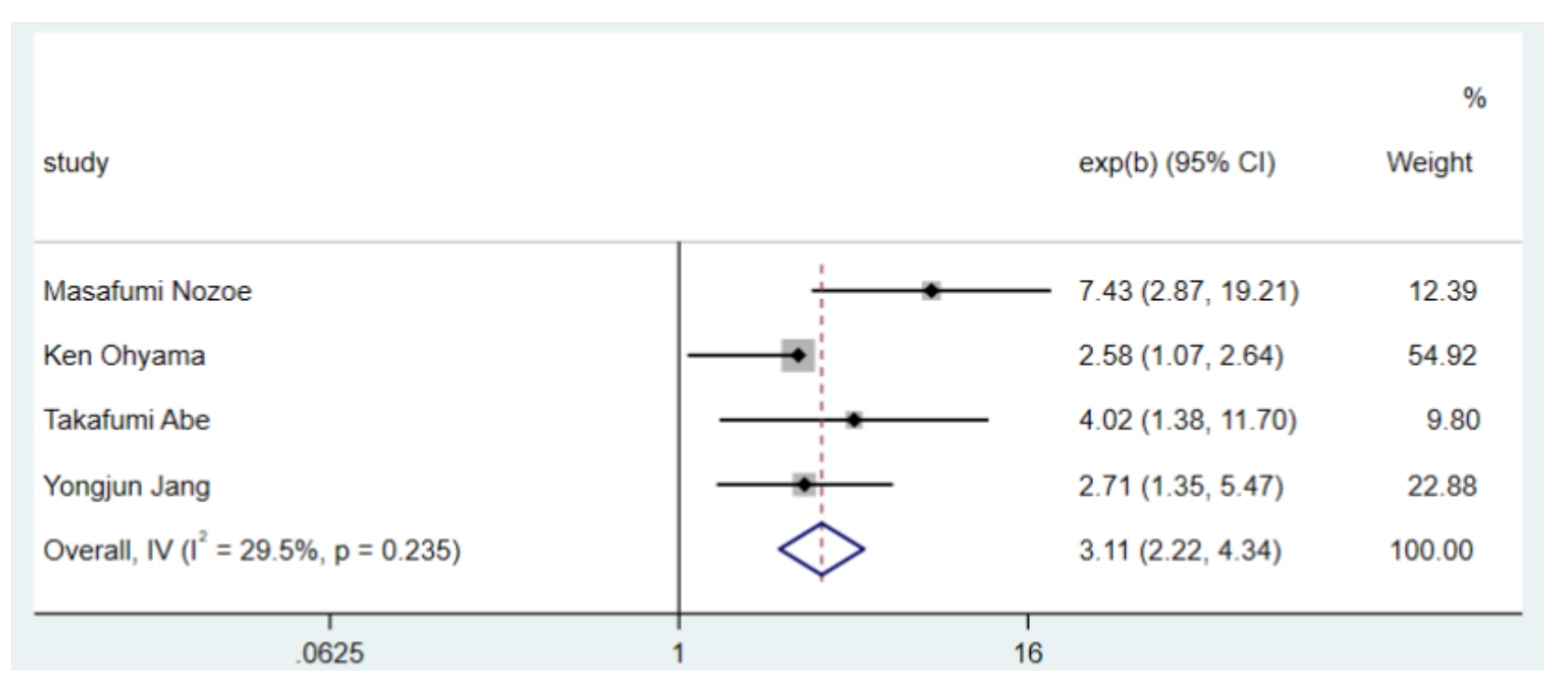

Figure 2. Forest plot for the modified Rankin Scale outcomes

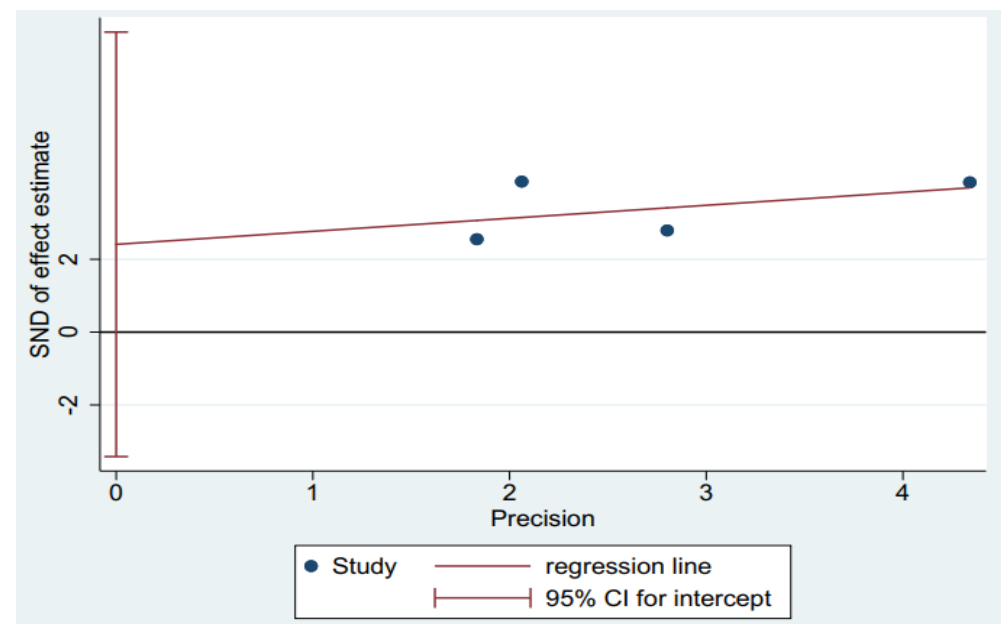

Figure 3. Publication bias-Harbord

of functional change after stroke. After adjusting for covariates, uGS was positively associated with dMBI $(\mathrm{P}<0.001)$.

\section{Functional Independence Measure - Motor domain (FIM-M)}

Three studies ${ }^{23-25}$ evaluated the relationship between sarcopenia and FIM-M. One of these studies ${ }^{23}$ showed that high muscle rate (skeletal muscle mass/body weight) (OR 2.42, 95\% CI 1.05-5.59; P=0.03) was significantly associated with a four-week FIM-M program among male and female patients. However, a study by Matsushita et al. $^{25}$ reported that a diagnosis of sarcopenia independently predicted FIM-M score (B -4.957, 95\% CI-9.902--0.012) at discharge in men, but not in women. Another study ${ }^{24}$ showed that changes in SMI were significantly associated with FIM-M at discharge $(\beta 0.175, \mathrm{P}=0.003)$.

\section{Publication bias}

There was no publication bias in the meta-analysis after using the Egger's test $(\mathrm{p}=0.217)$ as displayed in Figure 3.

\section{Discussion}

A wide variety of tests and tools for the assessment of sarcopenia are currently available $e^{26,27}$. To date, the revised guideline published by the European Working Group on Sarcopenia in Older People (EWGSOP2) propose new insights that muscle strength is the principal determinant of sarcopenia as opposed to muscle mass ${ }^{3}$. The assessment of skeletal muscle strength includes grip strength and chair stand test. Muscle strength is better than muscle mass in predicting poor clinical outcomes in patients ${ }^{28-30}$. In our study, five of the eight included studies used grip strength measurement. Moreover, one of the studies used the SARC-F to assess sarcopenia. Researchers have 
reported that the scale has low to moderate sensitivity and high specificity in predicting low muscle strength ${ }^{31}$. The SARC-F is a self-reported questionnaire by patients that contains five areas of strength, assistance in walking, rising from a chair, climbing stairs, and falls ${ }^{32}$. Finally, two studies used bioelectrical impedance analysis (BIA) to assess skeletal muscle mass in consideration of the level of disability, consciousness, or cognitive impairment of the stroke patients. The method was chosen also due to the convenience, inexpensiveness, and accessibility. In short, the manner, in which sarcopenia was assessed by the eight studies was reasonable. The appropriate assessment method was selected based on the patient's disability or mobility, the resources available in the medical setting, or the purpose of the test as well.

We were interested in finding out whether sarcopenia occurred prior to stroke or post stroke. However, only one study ${ }^{18}$ explicitly stated that the condition existed pre-stroke in relation to functional outcome. The rest of the literature assessed sarcopenia within seven days after admission to the hospital without delineation of the specific time when it happened. Nevertheless, all studies showed that sarcopenia was related to physical function of patients with stroke. It is worth noting that gender differences and stroke severity should be considered when predicting physical function in patients with stroke. As mentioned previously, one study ${ }^{25}$ only identified this correlation in the male gender. In contrast, another study ${ }^{21}$ concluded that women presenting with sarcopenia within 2 weeks of a stroke had a higher risk for poor prognosis than men. This discrepancy might be due to different methods used in the studies to assess sarcopenia and physical function, different follow-up times, and the presence of confounding factors such as disease severity, nutrition, etc. Moreover, the examination by Abe et $\mathrm{al}^{20}$ on the effect of skeletal muscle mass on walking function indicated that it could vary by disease severity. Physical function was worse in the mild and moderate groups with lower skeletal muscle mass, but no such relationship was found in the severe group. A possible reason for this was that the severity of stroke had a greater impact on walking function than sarcopenia in the severe group.

Stroke and sarcopenia are two different chronically disabling diseases affecting each other. Skeletal muscle is the main effector organ causing disability due to immobility after stroke. Decreased skeletal muscle mass eventually results in impaired mobility and decreased physical performance $^{33}$. This study found that sarcopenia was also related to an increased risk of poor physical function as assessed by $\mathrm{mRS}$ in patients with stroke (OR=3.11, 95\% CI: 2.22-4.34, $\mathrm{P}<0.0001)$. Currently, several factors in research reports were used to predict the prognosis of stroke. Malnutrition, a cause of sarcopenia, also might be a predictor of poor functional outcome of stroke $\mathrm{s}^{34-36}$. This indirectly supported our findings that sarcopenia was an independent factor predicting physical function outcome of patients with stroke. Recent studies ${ }^{12}$ reported there was a negative correlation between sarcopenia and improvement in ADLs in the rehabilitation setting. Our finding concurred with those of the studies as well.

\section{Implications for practice}

Our study found that sarcopenia was correlated with physical functional status of patients with stroke. The ability to perform ADLs was essential for the improvement of the quality of life for stroke patients and their families. Previous studies showed that increased nutritional or exercise interventions could improve the muscle mass, strength, and physical function of patients with sarcopenia and stroke ${ }^{37,38}$. Increased muscle mass was found to improve ADLs, which was important for stroke rehabilitation. It highlighted the significance of managing skeletal muscle mass of this population.

Sarcopenia is not a consideration in current recommendations for stroke treatment and rehabilitation guidelines. Measurement tools for sarcopenia are infrequently used in the clinical setting ${ }^{39,40}$. Considering this situation, we strongly suggest that screening, diagnosis, treatment, and prevention of sarcopenia should be part of the routine clinical practice in patients with stroke.

\section{Limitations}

This study has some limitations. Firstly, several different definitions and measures were used to determine sarcopenia or physical functional outcomes. In addition, there was no defined threshold for muscle mass loss for patients with stroke 4 . Secondly, because some studies utilized a retrospective approach, there might be unexplored confounders, such as rehabilitation and psychiatric symptoms, which might affect physical functional prognosis. Thirdly, majority of the studies had follow-up periods ending at discharge, which was a short length of time. Future studies should require longer followup periods.

\section{Conclusion}

This review provided an overview of the available literature identifying the relationship between sarcopenia and physical functional outcomes of patients with stroke. Early identification of sarcopenia in stroke patients is imperative for outcome improvement. We are hoping to see further investigations into the disease mechanism as well as more research on sarcopenia as a clinical outcome predictor among this patient population.

\section{Conflict of Interest}

The authors declare no conflict of interest. 


\section{Funding}

This study received no special grant from any funding agency.

\section{References}

1. Su Y, Michiko Y, Mika O. "Prevalence of stroke-related sarcopenia: A systematic review and meta-analysis." J Stroke Cerebrovasc Dis. 2020 105092.

2. Yoshimura Y, Wakabayashi H, Bise T, et al. Prevalence of sarcopenia and its association with activities of daily living and dysphagia in convalescent rehabilitation ward inpatients. Clin Nutr. 2018 Dec;37(6 Pt A):2022-2028.

3. Cruz-Jentoft AJ, Bahat G, Bauer J, et al. Sarcopenia: revised European consensus on definition and diagnosis. Age Ageing. 2019;48:16-31.

4. Scherbakov N, Sandek A, Doehner W. Stroke-related sarcopenia: specific characteristics. J Am Med Dir Assoc. 2015 Apr;16(4):272-6.

5. Chang KV, Hsu TH, Wu WT, et al. Association between sarcopenia and cognitive impairment: A systematic review and meta-analysis. J Am Med Dir Assoc. 2016;17(12):1164.e7-1164.e15.

6. Beaudart C, Zaaria M, Pasleau F, et al. Health outcomes of sarcopenia: A systematic review and meta-analysis. Plos One. 2017 Jan 17;12(1):e0169548

7. Chang SF, Lin PL. Systematic literature review and meta-analysis of the association of sarcopenia with mortality. Worldviews Evid Based Nurs. 2016 Apr;13(2):153-62

8. GBD 2015 Neurological Disorders Collaborator Group. Global, regional, and national burden of neurological disorders during 19902015: a systematic analysis for the Global Burden of Disease Study 2015. Lancet Neurol. 2017 Nov;16(11):877-897.

9. Katan M, Luft A. Global Burden of Stroke. Semin Neurol. 2018 Apr;38(2):208-211.

10. Morandi A, Onder G, Fodri L, et al. The association between the probability of sarcopenia and functional outcomes in older patients undergoing in-hospital rehabilitation. J Am Med Dir Assoc. 2015 Nov 1;16(11):951-6

11. Landi F, Calvani R, Ortolani E, et al. The association between sarcopenia and functional outcomes among older patients with hip fracture undergoing in-hospital rehabilitation. Osteoporos Int. 2017 May;28(5):1569-1576.

12. Yoshimura Y, Wakabayashi H, Bise T, et al. Sarcopenia is associated with worse recovery of physical function and dysphagia and a lower rate of home discharge in Japanese hospitalized adults undergoing convalescent rehabilitation. Nutrition. 2019 May;61:111-118.

13. Weimar C, König IR, Kraywinkel K, et al. Age and National Institutes of Health Stroke Scale Score within 6 hours after onset are accurate predictors of outcome after cerebral ischemia: development and external validation of prognostic models. Stroke. 2004 Jan;35(1):15862.

14. Wells GA, Shea B, O'Connell D, et al. The Newcastle-Ottawa Scale (NOS) for assessing the quality of nonrandomised studies in meta-analyses. The Ottawa Hospital Research Institute. 2014. http://www.ohri.ca/ programs/clinical_epidemiology/oxford.asp (accessed December 14, 2015).

15. Higgins JP, Thompson SG. Quantifying heterogeneity in a metaanalysis. Stat Med. 2002 Jun 15;21(11):1539-58.

16. Egger M, Davey Smith G, Schneider M, et al. Bias in meta-analysis detected by a simple, graphical test. BMJ. 1997 Sep 13;315(7109):62934.

17. PRISMA. (n.d.). PRISMA transparent reporting of systematic reviews and meta-analyses. Retrieved October 10, 2017, from www.prismastatement.org

18. Nozoe M, Kanai M, Kubo H, et al. Pre-stroke sarcopenia and functional outcomes in elderly patients who have had an acute stroke: A prospective cohort study. Nutrition. 2019 Oct;66:44-47.

19. Ohyama K, Watanabe M, Nosaki Y, et al. Correlation between skeletal muscle mass deficitand poor functional outcome in patients with acute ischemic stroke. J Stroke Cerebrovasc Dis. 2020 Apr;29(4):104623.

20. Abe T, Iwata K, Yoshimura Y, et al. Low muscle mass is associated with walking function in patients with acute ischemic stroke. J Stroke Cerebrovasc Dis. 2020 Nov;29(11):105259.

21. Jang Y, Im S, Han Y, et al. Can initial sarcopenia affect poststroke rehabilitation outcome? J Clin Neurosci. 2020 Jan;71:113-118.

22. Yi Y, Shim JS, Oh BM, et al. Grip strength on the unaffected side as an independent predictor of functional improvement after stroke. Am J Phys Med Rehabil. 2017 Sep;96(9):616-620.

23. Irisawa $\mathrm{H}$, Mizushima $\mathrm{T}$. Correlation of body composition and nutritional status with functional recovery in stroke rehabilitation patients. Nutrients. 2020 Jun 29;12(7):1923.

24. Nagano F, Yoshimura Y, Bise T, et al. Muscle mass gain is positively associated with functional recovery in patients with sarcopenia after stroke. J Stroke Cerebrovasc Dis. 2020 Sep;29(9):105017.

25. Matsushita T, Nishioka S, Taguchi S, et al. Sarcopenia as a predictor of activities of daily living capability in stroke patients undergoing rehabilitation. Geriatr Gerontol Int. 2019 Nov;19(11):1124-1128.

26. Reginster JY, Cooper C, Rizzoli R, et al. Recommendations for the conduct of clinical trials for drugs to treat or prevent sarcopenia. Aging Clin Exp Res. 2016 Feb;28(1):47-58.

27. Mijnarends DM, Meijers JM, Halfens RJ, et al. Validity and reliability of tools to measure muscle mass, strength, and physical performance in community-dwelling older people: A systematic review. J Am Med Dir Assoc. 2013 Mar;14(3):170-8.

28. Schaap LA, Koster A, Visser M. Adiposity, muscle mass, and muscle strength in relation to functional decline in older persons. Epidemiol Rev. 2013;35:51-65.

29. Leong DP, Teo KK, Rangarajan S, et al. Prognostic value of grip strength: findings from the prospective urban rural epidemiology (PURE) study. Lancet. 2015 Jul 18;386(9990):266-73.

30. Ibrahim K, May C, Patel HP, et al. A feasibility study of implementing grip strength measurement into routine hospital practice (GRImP): study protocol. Pilot Feasibility Stud. 2016 Jun 6;2:27.

31. Bahat G, Yilmaz O, Kılıç C, et al. Performance of SARC-F in regard to sarcopenia definitions, muscle mass and functional measures. J Nutr Health Aging. 2018;22(8):898-903.

32. Malmstrom TK, Miller DK, Simonsick EM, et al. SARC-F: a symptom score to predict persons with sarcopenia at risk for poor functional outcomes. J Cachexia Sarcopenia Muscle. 2016 Mar;7(1):28-36.

33. Ryan AS, Ivey FM, Serra MC, et al. Sarcopenia and physical function in middle-aged and older stroke survivors. Arch Phys Med Rehabil. 2017 Mar;98(3):495-499.

34. Kawase $\mathrm{S}$, Kowa $\mathrm{H}$, Suto $\mathrm{Y}$, et al. Association between body mass index and outcome in Japanese ischemic stroke patients. Geriatr Gerontol Int. 2017 Mar; 17(3):369-374.

35. Naito $\mathrm{H}, \mathrm{Nezu}$ T, Hosomi N, et al. Controlling nutritional status score for predicting 3-mo functional outcome in acute ischemic stroke. Nutrition. 2018 Nov;55-56:1-6.

36. Kishimoto H, Yozu A, Kohno Y, et al. Nutritional improvement is associated with better functional outcome in stroke rehabilitation: A cross-sectional study using controlling nutritional status. J Rehabil Med. 2020 Mar 18;52(3):jrm00029. 
37. Yoshimura Y, Bise T, Shimazu S, et al. Effects of a leucine-enriched amino acid supplement on muscle mass, muscle strength, and physical function in post-stroke patients with sarcopenia: A randomized controlled trial. Nutrition. 2019 Feb;58:1-6.

38. Ikeda T, Morotomi N, Kamono A, et al. The effects of timing of a leucine-enriched amino acid supplement on body composition and physical function in stroke patients: A randomized controlled trial. Nutrients. 2020 Jun 29;12(7):1928.
39. Powers WJ, Rabinstein AA, Ackerson T, et al. Guidelines for the early management of patients with acute ischemic stroke: 2019 ipdate to the 2018 guidelines for the early management of acute ischemic stroke: A guideline for healthcare professionals from the American Heart Association/American Stroke Association. Stroke. 2019 Dec;50(12):e344-e418.

40. Gittler M, Davis AM. Guidelines for adult stroke rehabilitation and recovery. JAMA. 2018 Feb 27;319(8):820-821. 